\title{
Coefficient Estimates for Two New Subclasses of Biunivalent Functions with respect to Symmetric Points
}

\author{
Şahsene Altınkaya and Sibel Yalçın \\ Department of Mathematics, Faculty of Arts and Science, Uludag University, 16059 Bursa, Turkey \\ Correspondence should be addressed to Şahsene Altınkaya; sahsenealtinkaya@gmail.com \\ Received 1 December 2014; Accepted 9 February 2015 \\ Academic Editor: Alberto Fiorenza
}

Copyright (C) 2015 Ş. Altınkaya and S. Yalçın. This is an open access article distributed under the Creative Commons Attribution License, which permits unrestricted use, distribution, and reproduction in any medium, provided the original work is properly cited.

We introduce two subclasses of biunivalent functions and find estimates on the coefficients $\left|a_{2}\right|$ and $\left|a_{3}\right|$ for functions in these new subclasses. Also, consequences of the results are pointed out.

\section{Introduction and Definitions}

Let $A$ denote the class of analytic functions in the unit disk

$$
U=\{z \in \mathbb{C}:|z|<1\}
$$

that have the form

$$
f(z)=z+\sum_{n=2}^{\infty} a_{n} z^{n}
$$

Further, by $S$ we will denote the class of all functions in $A$ which are univalent in $U$.

The Koebe one-quarter theorem [1] states that the image of $U$ under every function $f$ from $S$ contains a disk of radius $(1 / 4)$. Thus every such univalent function has an inverse $f^{-1}$ which satisfies

$$
\begin{gathered}
f^{-1}(f(z))=z, \quad(z \in U), \\
f\left(f^{-1}(w)\right)=w, \quad\left(|w|<r_{0}(f), r_{0}(f) \geq \frac{1}{4}\right),
\end{gathered}
$$

where

$$
\begin{aligned}
f^{-1}(w)= & w-a_{2} w^{2}+\left(2 a_{2}^{2}-a_{3}\right) w^{3} \\
& -\left(5 a_{2}^{3}-5 a_{2} a_{3}+a_{4}\right) w^{4}+\cdots .
\end{aligned}
$$

A function $f(z) \in A$ is said to be biunivalent in $U$ if both $f(z)$ and $f^{-1}(z)$ are univalent in $U$. Let $\Sigma$ denote the class of biunivalent functions defined in the unit $\operatorname{disk} U$.
If the functions $f$ and $g$ are analytic in $U$, then $f$ is said to be subordinate to $g$, written as

$$
f(z) \prec g(z), \quad(z \in U)
$$

if there exists a Schwarz function $w(z)$, analytic in $U$, with

$$
w(0)=0, \quad|w(z)|<1 \quad(z \in U)
$$

such that

$$
f(z)=g(w(z)) \quad(z \in U) .
$$

Lewin [2] studied the class of biunivalent functions, obtaining the bound 1.51 for modulus of the second coefficient $\left|a_{2}\right|$. Subsequently, Netanyahu [3] showed that $\max \left|a_{2}\right|=$ $4 / 3$ if $f(z) \in \Sigma$. Brannan and Clunie [4] conjectured that $\left|a_{2}\right| \leq \sqrt{2}$ for $f \in \Sigma$. Brannan and Taha [5] introduced certain subclasses of the biunivalent function class $\Sigma$ similar to the familiar subclasses of univalent functions consisting of strongly starlike, starlike, and convex functions. They introduced bistarlike functions and obtained estimates on the initial coefficients. Bounds for the initial coefficients of several classes of functions were also investigated in [6-15].

Not much is known about the bounds on the general coefficient $\left|a_{n}\right|$ for $n \geq 4$. In the literature, there are only a few works determining the general coefficient bounds $\left|a_{n}\right|$ for the analytic biunivalent functions ([16-20]). The coefficient estimate problem for each of $\left|a_{n}\right|(n \in \mathbb{N} \backslash\{1,2\} ; \mathbb{N}=$ $\{1,2,3, \ldots\})$ is still an open problem. 
By $S^{*}(\phi)$ and $C(\phi)$ we denote the following classes of functions:

$$
\begin{gathered}
S^{*}(\phi)=\left\{f: f \in A, \frac{z f^{\prime}(z)}{f(z)} \prec \phi(z) ; z \in U\right\}, \\
C(\phi)=\left\{f: f \in A, 1+\frac{z f^{\prime \prime}(z)}{f^{\prime}(z)} \prec \phi(z) ; z \in U\right\} .
\end{gathered}
$$

The classes $S^{*}(\phi)$ and $C(\phi)$ are the extensions of classical sets of starlike and convex functions and in such form were defined and studied by Ma and Minda [21].

In [22], Sakaguchi introduced the class $S_{S}^{*}$ of starlike functions with respect to symmetric points in $U$, consisting of functions $f \in A$ that satisfy the condition $\operatorname{Re}\left(z f^{\prime}(z) /(f(z)-\right.$ $f(-z)))>0, z \in U$. Similarly, in [23], Wang et al. introduced the class $C_{S}$ of convex functions with respect to symmetric points in $U$, consisting of functions $f \in A$ that satisfy the condition $\operatorname{Re}\left(\left(z f^{\prime}(z)\right)^{\prime} /\left(f^{\prime}(z)+f^{\prime}(-z)\right)\right)>0, z \in U$. In the style of Ma and Minda, Ravichandran (see [24]) defined the classes $S_{S}^{*}(\phi)$ and $C_{S}(\phi)$.

A function $f \in A$ is in the class $S_{S}^{*}(\phi)$ if

$$
\frac{2 z f^{\prime}(z)}{f(z)-f(-z)} \prec \phi(z), \quad z \in U,
$$

and in the class $C_{S}(\phi)$ if

$$
\frac{2\left(z f^{\prime}(z)\right)^{\prime}}{f^{\prime}(z)+f^{\prime}(-z)} \prec \phi(z), \quad z \in U
$$

In this paper, we introduce two new subclasses of biunivalent functions. Further, we find estimates on the coefficients $\left|a_{2}\right|$ and $\left|a_{3}\right|$ for functions in these subclasses.

\section{Coefficient Estimates for the Function}

$$
\text { Class } S_{S, \Sigma}^{*}(\alpha, h)
$$

Definition 1. Let the functions $h, p: U \rightarrow \mathbb{C}$ be so constrained that

$$
\begin{gathered}
\min \{\operatorname{Re}(h(z)), \operatorname{Re}(p(z))\}>0, \\
h(0)=p(0)=1 .
\end{gathered}
$$

Definition 2. A function $f \in \Sigma$ is said to be in the class $S_{S, \Sigma}^{*}(\alpha, h)$ if the following conditions are satisfied:

$$
\begin{aligned}
& \frac{2\left[(1-\alpha) z f^{\prime}(z)+\alpha z\left(z f^{\prime}(z)\right)^{\prime}\right]}{(1-\alpha)(f(z)-f(-z))+\alpha z\left(f^{\prime}(z)+f^{\prime}(-z)\right)} \in h(U), \\
& \frac{2\left[(1-\alpha) w g^{\prime}(w)+\alpha w\left(w g^{\prime}(w)\right)^{\prime}\right]}{(1-\alpha)(g(w)-g(-w))+\alpha w\left(g^{\prime}(w)+g^{\prime}(-w)\right)} \in p(U),
\end{aligned}
$$

where $g(w)=f^{-1}(w)$.
Definition 3. One notes that, for $\alpha=0$, one gets the class $S_{S}^{*}(h)$ which is defined as follows:

$$
\begin{aligned}
& \frac{2 z f^{\prime}(z)}{f(z)-f(-z)} \in h(U), \\
& \frac{2 w g^{\prime}(w)}{g(w)-g(-w)} \in p(U) .
\end{aligned}
$$

Theorem 4. Let $f$ given by (2) be in the class $S_{S, \Sigma}^{*}(\alpha, h)$. Then

$$
\begin{aligned}
& \quad\left|a_{2}\right| \\
& \leq \min \left\{\sqrt{\frac{\left|h^{\prime}(0)\right|^{2}+\left|p^{\prime}(0)\right|^{2}}{8(1+\alpha)^{2}}}, \sqrt{\frac{\left|h^{\prime \prime}(0)\right|+\left|p^{\prime \prime}(0)\right|}{8(1+2 \alpha)}}\right\}, \\
& \left|a_{3}\right| \leq \min \left\{\frac{\left|h^{\prime}(0)\right|^{2}+\left|p^{\prime}(0)\right|^{2}}{8(1+\alpha)^{2}}\right. \\
& \left.+\frac{\left|h^{\prime \prime}(0)\right|+\left|p^{\prime \prime}(0)\right|}{8(1+2 \alpha)}, \frac{\left|h^{\prime \prime}(0)\right|}{4(1+2 \alpha)}\right\} .
\end{aligned}
$$

Proof. Let $f \in S_{S, \Sigma}^{*}(\alpha, h)$ and $g$ be the analytic extension of $f^{-1}$ to $U$. It follows from (12) that

$$
\frac{2\left(z f^{\prime}(z)+\alpha z^{2} f^{\prime \prime}(z)\right)}{(1-\alpha)(f(z)-f(-z))+\alpha z\left(f^{\prime}(z)+f^{\prime}(-z)\right)}=h(z),
$$

$(z \in U)$

$$
\frac{2\left(w g^{\prime}(w)+\alpha w^{2} g^{\prime \prime}(w)\right)}{(1-\alpha)(g(w)-g(-w))+\alpha w\left(g^{\prime}(w)+g^{\prime}(-w)\right)}=p(w),
$$

$(w \in U)$,

where $h(z)$ and $p(w)$ satisfy the conditions of Definition 1 . Furthermore, the functions $h(z)$ and $p(w)$ have the following Taylor-Maclaurin series expansions:

$$
\begin{gathered}
h(z)=1+h_{1} z+h_{2} z^{2}+\cdots, \\
p(w)=1+p_{1} w+p_{2} w^{2}+\cdots,
\end{gathered}
$$

respectively. From (15), we deduce

$$
\begin{gathered}
2(1+\alpha) a_{2}=h_{1}, \\
2(1+2 \alpha) a_{3}=h_{2}, \\
-2(1+\alpha) a_{2}=p_{1}, \\
2(1+2 \alpha)\left(2 a_{2}^{2}-a_{3}\right)=p_{2} .
\end{gathered}
$$

From (18) and (20) we obtain

$$
h_{1}=-p_{1},
$$

$$
8(1+\alpha)^{2} a_{2}^{2}=h_{1}^{2}+p_{1}^{2} .
$$


By adding (19) to (21), we get

$$
4(1+2 \alpha) a_{2}^{2}=h_{2}+p_{2} .
$$

Therefore, we find from (23) and (24) that

$$
\begin{aligned}
& \left|a_{2}\right|^{2} \leq \frac{\left|h^{\prime}(0)\right|^{2}+\left|p^{\prime}(0)\right|^{2}}{8(1+\alpha)^{2}}, \\
& \left|a_{2}\right|^{2} \leq \frac{\left|h^{\prime \prime}(0)\right|+\left|p^{\prime \prime}(0)\right|}{8(1+2 \alpha)} .
\end{aligned}
$$

Subtracting (21) from (19) we have

$$
4(1+2 \alpha) a_{3}-4(1+2 \alpha) a_{2}^{2}=h_{2}-p_{2}
$$

Then, upon substituting the value of $a_{2}^{2}$ from (23) and (24) into (26), it follows that

$$
\begin{aligned}
& a_{3}=\frac{h_{1}^{2}+p_{1}^{2}}{8(1+\alpha)^{2}}+\frac{h_{2}-p_{2}}{4(1+2 \alpha)}, \\
& a_{3}=\frac{h_{2}+p_{2}}{4(1+2 \alpha)}+\frac{h_{2}-p_{2}}{4(1+2 \alpha)} .
\end{aligned}
$$

We thus find that

$$
\begin{gathered}
\left|a_{3}\right| \leq \frac{\left|h^{\prime}(0)\right|^{2}+\left|p^{\prime}(0)\right|^{2}}{8(1+\alpha)^{2}}+\frac{\left|h^{\prime \prime}(0)\right|+\left|p^{\prime \prime}(0)\right|}{8(1+2 \alpha)}, \\
\left|a_{3}\right| \leq \frac{\left|h^{\prime \prime}(0)\right|}{4(1+2 \alpha)} .
\end{gathered}
$$

This completes the proof of Theorem 4 .

Taking $\alpha=0$ we get the following.

Corollary 5. If $f \in S_{S}^{*}(h)$ then

$$
\begin{gathered}
\left|a_{2}\right| \leq \min \left\{\sqrt{\frac{\left|h^{\prime}(0)\right|^{2}+\left|p^{\prime}(0)\right|^{2}}{8}}, \sqrt{\frac{\left|h^{\prime \prime}(0)\right|+\left|p^{\prime \prime}(0)\right|}{8}}\right\}, \\
\left|a_{3}\right| \leq \min \left\{\frac{\left|h^{\prime}(0)\right|^{2}+\left|p^{\prime}(0)\right|^{2}}{8}\right. \\
\left.+\frac{\left|h^{\prime \prime}(0)\right|+\left|p^{\prime \prime}(0)\right|}{8}, \frac{\left|h^{\prime \prime}(0)\right|}{4}\right\} .
\end{gathered}
$$

Corollary 6. If we let

$$
\phi(z)=\left(\frac{1+z}{1-z}\right)^{\beta}=1+2 \beta z+2 \beta^{2} z^{2}+\cdots \quad(0<\beta \leq 1),
$$

then inequalities (14) become

$$
\begin{gathered}
\left|a_{2}\right| \leq \min \left\{\frac{\beta}{1+\alpha}, \frac{\beta}{\sqrt{1+2 \alpha}}\right\}, \\
\left|a_{3}\right| \leq \min \left\{\frac{\beta^{2}}{(1+\alpha)^{2}}+\frac{\beta^{2}}{1+2 \alpha}, \frac{\beta^{2}}{1+2 \alpha}\right\} .
\end{gathered}
$$

Corollary 7. If we let

$$
\begin{aligned}
\phi(z)= & \frac{1+(1-2 \beta) z}{1-z}=1+2(1-\beta) z \\
& +2(1-\beta) z^{2}+\cdots \quad(0 \leq \beta<1),
\end{aligned}
$$

then inequalities (14) become

$$
\begin{gathered}
\left|a_{2}\right| \leq \min \left\{\frac{1-\beta}{1+\alpha}, \sqrt{\frac{1-\beta}{1+2 \alpha}}\right\}, \\
\left|a_{3}\right| \leq \min \left\{\frac{(1-\beta)^{2}}{(1+\alpha)^{2}}+\frac{1-\beta}{1+2 \alpha}, \frac{1-\beta}{1+2 \alpha}\right\} .
\end{gathered}
$$

Remark 8. Corollaries 6 and 7 provide an improvement of the estimate $\left|a_{3}\right|$ obtained by Altınkaya and Yalçın [25].

Remark 9. The estimates on the coefficients $\left|a_{2}\right|$ and $\left|a_{3}\right|$ of Corollaries 6 and 7 are improvement of the estimates in [7].

\section{Coefficient Estimates for the Function$$
\text { Class } \mathfrak{E}_{S, \Sigma}(\alpha, h)
$$

Definition 10. A function $f \in \Sigma$ is said to be $\mathfrak{E}_{S, \Sigma}(\alpha, h)$ if the following conditions are satisfied:

$$
\begin{gathered}
\left(\frac{2 z f^{\prime}(z)}{f(z)-f(-z)}\right)^{\alpha}\left(\frac{2\left(z f^{\prime}(z)\right)^{\prime}}{f^{\prime}(z)+f^{\prime}(-z)}\right)^{1-\alpha} \in h(z), \\
\left(\frac{2 w g^{\prime}(w)}{g(w)-g(-w)}\right)^{\alpha}\left(\frac{2\left(w g^{\prime}(w)\right)^{\prime}}{g^{\prime}(w)+g^{\prime}(-w)}\right)^{1-\alpha} \in p(w),
\end{gathered}
$$

where $g(w)=f^{-1}(w)$.

We note that, for $\alpha=1$, the class $\mathfrak{E}_{S, \Sigma}(\alpha, h)$ reduces to the class $S_{S}^{*}(h)$.

Definition 11. One notes that, for $\alpha=0$, one gets the class $C_{S}(h)$ which is defined as follows:

$$
\begin{aligned}
& \frac{2\left(z f^{\prime}(z)\right)^{\prime}}{f^{\prime}(z)+f^{\prime}(-z)} \in h(U), \\
& \frac{2\left(w g^{\prime}(w)\right)^{\prime}}{g^{\prime}(w)+g^{\prime}(-w)} \in p(U) .
\end{aligned}
$$


Theorem 12. Let $f$ given by (2) be in the class $\mathfrak{E}_{S, \Sigma}(\alpha, h)$. Then

$$
\begin{array}{r}
\left|a_{2}\right| \leq \min \left\{\sqrt{\frac{\left|h^{\prime}(0)\right|^{2}+\left|p^{\prime}(0)\right|^{2}}{8(2-\alpha)^{2}}}, \sqrt{\frac{\left|h^{\prime \prime}(0)\right|+\left|p^{\prime \prime}(0)\right|}{8\left(3-3 \alpha+\alpha^{2}\right)}}\right\}, \\
\left|a_{3}\right| \leq \min \left\{\frac{\left|h^{\prime}(0)\right|^{2}+\left|p^{\prime}(0)\right|^{2}}{8(2-\alpha)^{2}}+\frac{\left|h^{\prime \prime}(0)\right|+\left|p^{\prime \prime}(0)\right|}{8(3-2 \alpha)},\right. \\
\left.\frac{\left(6-5 \alpha+\alpha^{2}\right)\left|h^{\prime \prime}(0)\right|+\left(\alpha-\alpha^{2}\right)\left|p^{\prime \prime}(0)\right|}{8(3-2 \alpha)\left(3-3 \alpha+\alpha^{2}\right)}\right\} .
\end{array}
$$

Proof. Let $f \in \mathfrak{E}_{S, \Sigma}(\alpha, h)$ and $g$ be the analytic extension of $f^{-1}$ to $U$. We have

$$
\begin{aligned}
& \left(\frac{2 z f^{\prime}(z)}{f(z)-f(-z)}\right)^{\alpha}\left(\frac{2\left(z f^{\prime}(z)\right)^{\prime}}{f^{\prime}(z)+f^{\prime}(-z)}\right)^{1-\alpha} \\
& =1+2(2-\alpha) a_{2} z \\
& \quad+\left[2(3-2 \alpha) a_{3}-2 \alpha(1-\alpha) a_{2}^{2}\right] z^{2}+\cdots \\
& \left(\frac{2 w g^{\prime}(w)}{g(w)-g(-w)}\right)^{\alpha}\left(\frac{2\left(w g^{\prime}(w)\right)^{\prime}}{g^{\prime}(w)+g^{\prime}(-w)}\right)^{1-\alpha} \\
& =1-2(2-\alpha) a_{2} w \\
& \quad+\left[2(3-2 \alpha)\left(2 a_{2}^{2}-a_{3}\right)-2 \alpha(1-\alpha) a_{2}^{2}\right] w^{2}+\cdots
\end{aligned}
$$

It follows from (34) that

$$
\begin{gathered}
\left(\frac{2 z f^{\prime}(z)}{f(z)-f(-z)}\right)^{\alpha}\left(\frac{2\left(z f^{\prime}(z)\right)^{\prime}}{f^{\prime}(z)+f^{\prime}(-z)}\right)^{1-\alpha}=h(z), \\
(z \in U), \\
\left(\frac{2 w g^{\prime}(w)}{g(w)-g(-w)}\right)^{\alpha}\left(\frac{2\left(w g^{\prime}(w)\right)^{\prime}}{g^{\prime}(w)+g^{\prime}(-w)}\right)^{1-\alpha}=p(w),
\end{gathered}
$$$$
(w \in U),
$$

where $h(z)$ and $p(w)$ satisfy the conditions of Definition 1.

From (39), we deduce

$$
\begin{gathered}
2(2-\alpha) a_{2}=h_{1} \\
2(3-2 \alpha) a_{3}-2 \alpha(1-\alpha) a_{2}^{2}=h_{2}, \\
-2(2-\alpha) a_{2}=p_{1} \\
2(3-2 \alpha)\left(2 a_{2}^{2}-a_{3}\right)-2 \alpha(1-\alpha) a_{2}^{2}=p_{2} .
\end{gathered}
$$

From (40) and (42) we obtain

$$
\begin{gathered}
h_{1}=-p_{1}, \\
8(2-\alpha)^{2} a_{2}^{2}=h_{1}^{2}+p_{1}^{2} .
\end{gathered}
$$

By adding (41) to (43), we get

$$
4\left(3-3 \alpha+\alpha^{2}\right) a_{2}^{2}=h_{2}+p_{2},
$$

which gives us the desired estimate on $\left|a_{2}\right|$ as asserted in (36). Subtracting (43) from (41) we have

$$
4(3-2 \alpha) a_{3}-4(3-2 \alpha) a_{2}^{2}=h_{2}-p_{2} .
$$

Then, in view of (45) and (46), it follows that

$$
\begin{gathered}
a_{3}=\frac{h_{1}^{2}+p_{1}^{2}}{8(2-\alpha)^{2}}+\frac{h_{2}-p_{2}}{4(3-2 \alpha)}, \\
a_{3}=\frac{h_{2}+p_{2}}{4\left(3-3 \alpha+\alpha^{2}\right)}+\frac{h_{2}-p_{2}}{4(3-2 \alpha)}
\end{gathered}
$$

as claimed. This completes the proof of Theorem 12 .

Taking $\alpha=0$ we get the following.

Corollary 13. If $f \in C_{S}(h)$ then

$$
\begin{gathered}
\left|a_{2}\right| \leq \min \left\{\sqrt{\frac{\left|h^{\prime}(0)\right|^{2}+\left|p^{\prime}(0)\right|^{2}}{32}}, \sqrt{\frac{\left|h^{\prime \prime}(0)\right|+\left|p^{\prime \prime}(0)\right|}{24}}\right\}, \\
\left|a_{3}\right| \leq \min \left\{\frac{\left|h^{\prime}(0)\right|^{2}+\left|p^{\prime}(0)\right|^{2}}{32}\right. \\
\left.+\frac{\left|h^{\prime \prime}(0)\right|+\left|p^{\prime \prime}(0)\right|}{24}, \frac{\left|h^{\prime \prime}(0)\right|}{12}\right\} .
\end{gathered}
$$

Corollary 14. If we let

$$
\phi(z)=\left(\frac{1+z}{1-z}\right)^{\beta}=1+2 \beta z+2 \beta^{2} z^{2}+\cdots \quad(0<\beta \leq 1),
$$

then inequalities (36) and (37) become

$$
\begin{gathered}
\left|a_{2}\right| \leq \min \left\{\frac{\beta}{2-\alpha}, \frac{\beta}{\sqrt{3-3 \alpha+\alpha^{2}}}\right\}, \\
\left|a_{3}\right| \leq \min \left\{\frac{\beta^{2}}{(2-\alpha)^{2}}+\frac{\beta^{2}}{3-2 \alpha}, \frac{\beta^{2}}{3-3 \alpha+\alpha^{2}}\right\} .
\end{gathered}
$$

Corollary 15. If we let

$$
\begin{aligned}
\phi(z)= & \frac{1+(1-2 \beta) z}{1-z}=1+2(1-\beta) z \\
& +2(1-\beta) z^{2}+\cdots \quad(0 \leq \beta<1),
\end{aligned}
$$


then inequalities (36) and (37) become

$$
\begin{gathered}
\left|a_{2}\right| \leq \min \left\{\frac{1-\beta}{2-\alpha}, \sqrt{\frac{1-\beta}{3-3 \alpha+\alpha^{2}}}\right\}, \\
\left|a_{3}\right| \leq \min \left\{\frac{(1-\beta)^{2}}{(2-\alpha)^{2}}+\frac{1-\beta}{3-2 \alpha}, \frac{1-\beta}{3-3 \alpha+\alpha^{2}}\right\} .
\end{gathered}
$$

Remark 16. Corollaries 14 and 15 provide an improvement of the estimate $\left|a_{3}\right|$ obtained by Altınkaya and Yalçın [25].

Remark 17. The estimates on the coefficients $\left|a_{2}\right|$ and $\left|a_{3}\right|$ of Corollaries 14 and 15 are improvement of the estimates obtained in [7].

\section{Conflict of Interests}

The authors declare that there is no conflict of interests regarding the publication of this paper.

\section{References}

[1] P. L. Duren, Univalent Functions, vol. 259 of Grundlehren der Mathematischen Wissenschaften, Springer, New York, NY, USA, 1983.

[2] M. Lewin, "On a coefficient problem for bi-univalent functions," Proceedings of the American Mathematical Society, vol. 18, pp. 63-68, 1967.

[3] E. Netanyahu, "The minimal distance of the image boundary from the orijin and the second coefficient of a univalent function in $|z|<1$," Archive for Rational Mechanics and Analysis, vol. 32, pp. 100-112, 1969.

[4] D. A. Brannan and J. G. Clunie, "Aspects of comtemporary complex analysis," in Proceedings of the NATO Advanced Study Institute Held at University of Durham: July 1-20, 1979, Academic Press, New York, NY, USA, 1980.

[5] D. A. Brannan and T. S. Taha, "On some classes of bi-univalent functions," Studia Universitatis Babeş-Bolyai. Mathematica, vol. 31, no. 2, pp. 70-77, 1986.

[6] S. Altinkaya and S. Yalcin, "Initial coefficient bounds for a general class of biunivalent functions," International Journal of Analysis, vol. 2014, Article ID 867871, 4 pages, 2014.

[7] O. Crişan, "Coefficient estimates for certain subclasses of biunivalent functions," General Mathematics Notes, vol. 16, no. 2, pp. 93-102, 2013.

[8] B. A. Frasin and M. K. Aouf, "New subclasses of bi-univalent functions," Applied Mathematics Letters, vol. 24, no. 9, pp. 15691573, 2011.

[9] B. S. Keerthi and B. Raja, "Coefficient inequality for certain new subclasses of analytic bi-univalent functions," Theoretical Mathematics and Applications, vol. 3, no. 1, pp. 1-10, 2013.

[10] S. S. Kumar, V. Kumar, and V. Ravichandran, "Estimates for the initial coefficients of Bi-univalent functions," http://arxiv.org/abs/1203.5480.

[11] N. Magesh and J. Yamini, "Coefficient bounds for certain subclasses of bi-univalent functions," International Mathematical Forum, vol. 8, no. 25-28, pp. 1337-1344, 2013.

[12] R. M. Ali, S. K. Lee, V. Ravichandran, and S. Supramaniam, "Coefficient estimates for bi-univalent Ma-MINda starlike and convex functions," Applied Mathematics Letters, vol. 25, no. 3, pp. 344-351, 2012.

[13] H. M. Srivastava, A. K. Mishra, and P. Gochhayat, "Certain subclasses of analytic and bi-univalent functions," Applied Mathematics Letters, vol. 23, no. 10, pp. 1188-1192, 2010.

[14] H. M. Srivastava, S. Bulut, M. Çaglar, and N. Yagmur, "Coefficient estimates for a general subclass of analytic and biunivalent functions," Filomat, vol. 27, no. 5, pp. 831-842, 2013.

[15] Q.-H. Xu, Y.-C. Gui, and H. M. Srivastava, "Coefficient estimates for a certain subclass of analytic and bi-univalent functions," Applied Mathematics Letters, vol. 25, no. 6, pp. 990-994, 2012.

[16] S. Altinkaya and S. Yalcin, "Coefficient bounds for a subclass of bi-univalent functions," TWMS Journal of Pure and Applied Mathematics. In press.

[17] S. Bulut, "Faber polynomial coefficient estimates for a comprehensive subclass of analytic bi-univalent functions," Comptes Rendus Mathematique, vol. 352, no. 6, pp. 479-484, 2014.

[18] S. G. Hamidi and J. M. Jahangiri, "Faber polynomial coefficient estimates for analytic bi-close-to-convex functions," Comptes Rendus Mathematique, vol. 352, no. 1, pp. 17-20, 2014.

[19] J. M. Jahangiri and S. G. Hamidi, "Coefficient estimates for certain classes of bi-univalent functions," International Journal of Mathematics and Mathematical Sciences, vol. 2013, Article ID 190560, 4 pages, 2013.

[20] J. M. Jahangiri, S. G. Hamidi, and S. A. Halim, "Coefficients of bi-univalent functions with positive real part derivatives," Bulletin of the Malaysian Mathematical Sciences Society, vol. 37, no. 3, pp. 633-640, 2014.

[21] W. C. Ma and D. Minda, "A unified treatment of some special classes of univalent functions," in Proceedings of the Conference on Complex Analysis (Tianjin, 1992), Z. Li, F. Ren, L. Yang, and S. Zhang, Eds., Conference Proceedings and Lecture Notes in Analysis, pp. 157-169, International Press, Cambridge, Mass, USA, 1994.

[22] K. Sakaguchi, "On a certain univalent mapping," Journal of the Mathematical Society of Japan, vol. 11, no. 1, pp. 72-75, 1959.

[23] Z.-G. Wang, C.-Y. Gao, and S.-M. Yuan, "On certain subclasses of close-to-convex and quasi-convex functions with respect to $k$-symmetric points," Journal of Mathematical Analysis and Applications, vol. 322, no. 1, pp. 97-106, 2006.

[24] V. Ravichandran, "Starlike and convex functions with respect to conjugate points," Acta Mathematica: Academiae Paedagogicae Nyıregyháziensis, vol. 20, no. 1, pp. 31-37, 2004.

[25] Ş. Altınkaya and S. Yalçın, "Fekete-Szegö Inequalities for certain classes of bi-univalent functions," International Scholarly Research Notices, vol. 2014, Article ID 327962, 6 pages, 2014. 


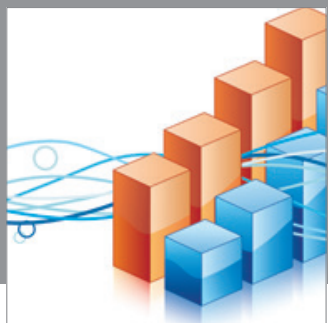

Advances in

Operations Research

mansans

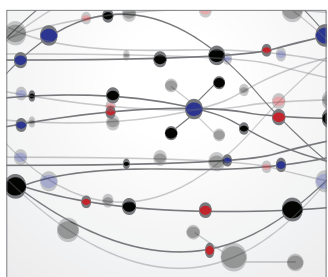

The Scientific World Journal
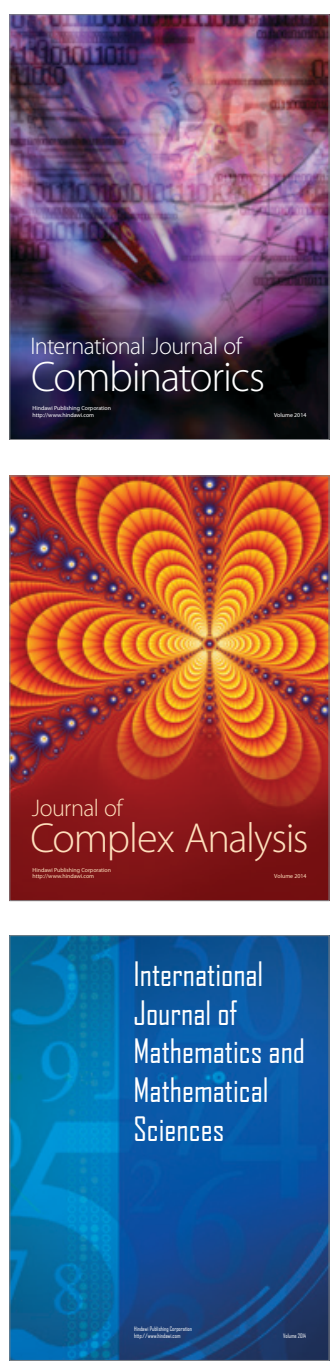
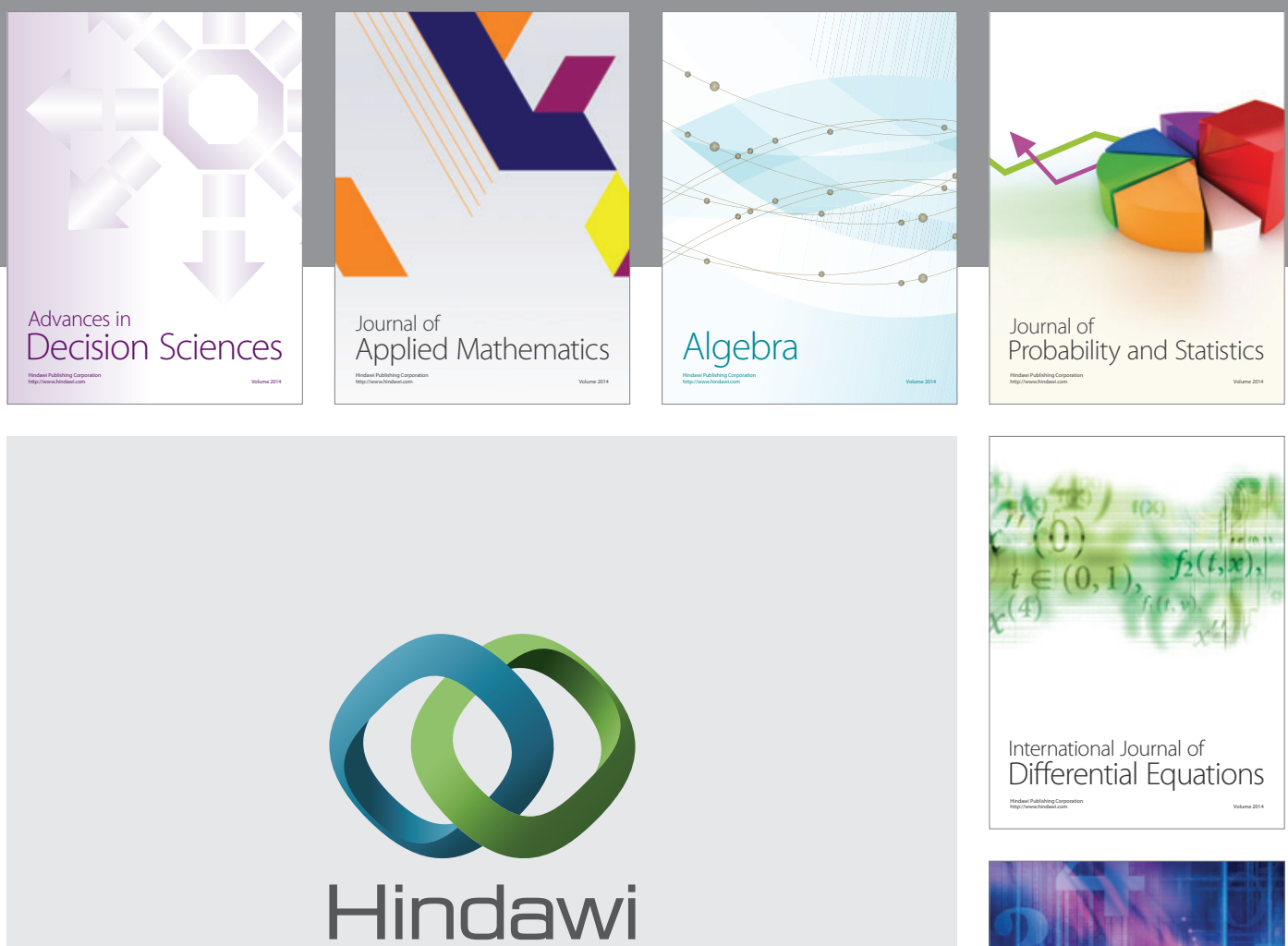

Submit your manuscripts at http://www.hindawi.com
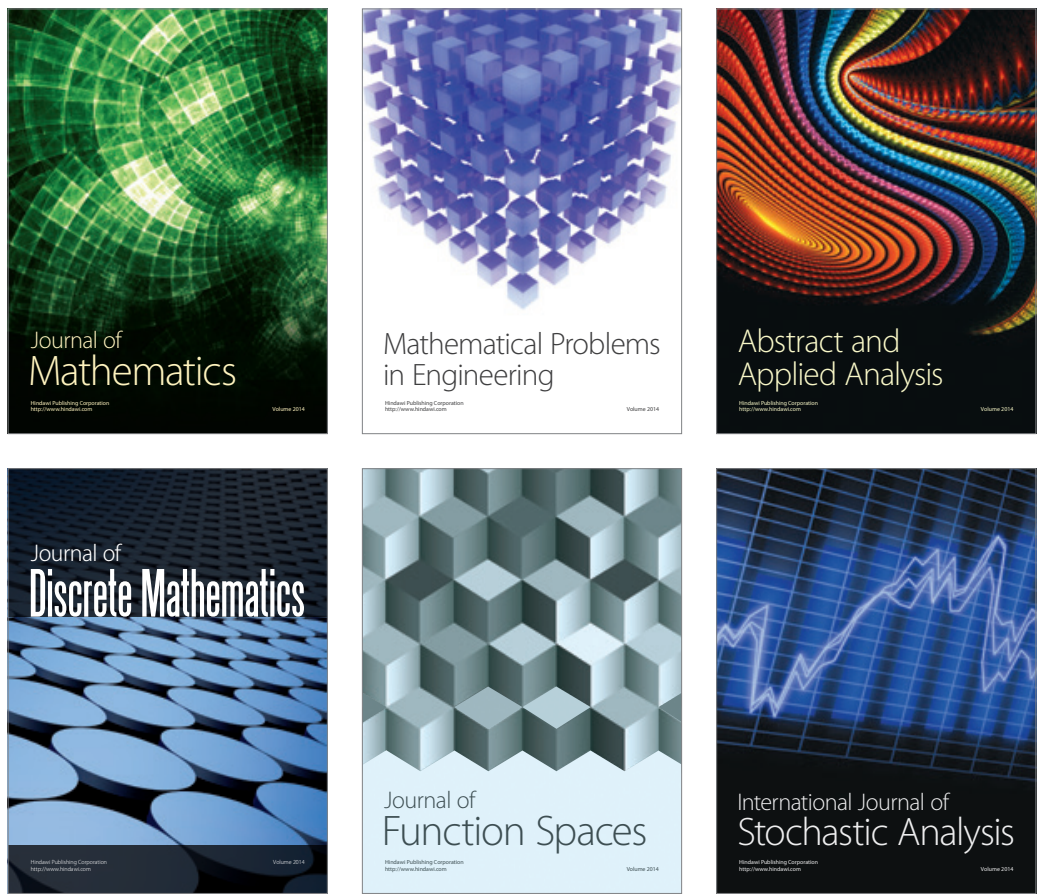

Journal of

Function Spaces

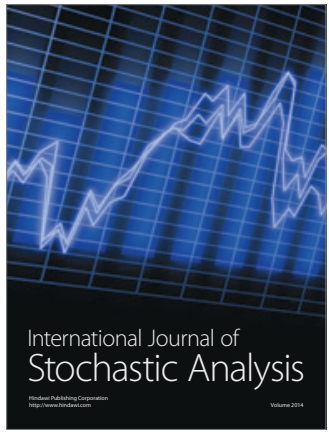

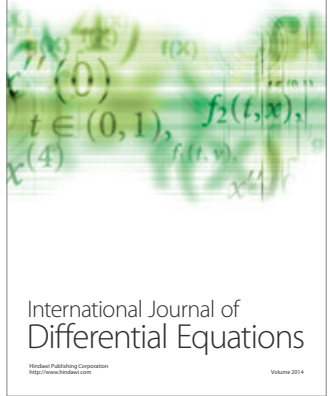
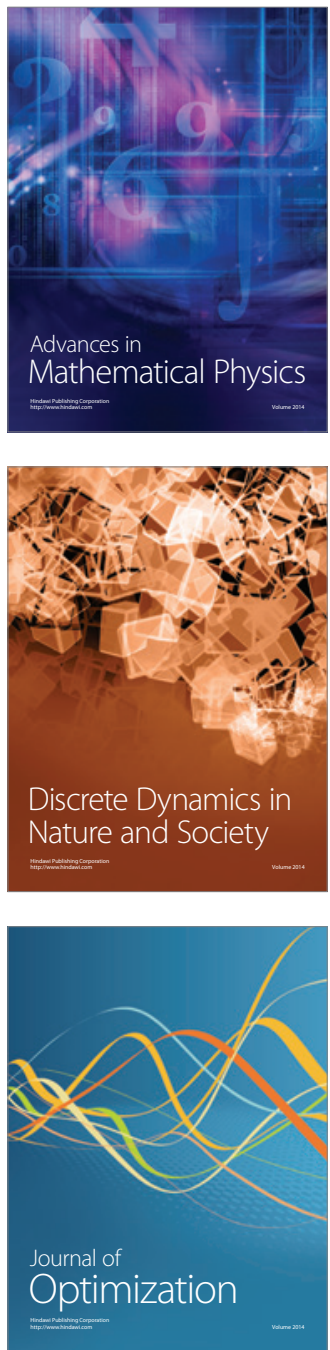